\title{
The Collapse Analysis of the Lateral-Torsional Buckling of I-Shaped Stepped Steel Beams
}

\author{
Kelsen Trista Kweenisky' ${ }^{*}$, Naomi Pratiwi, Paulus Karta Wijaya \\ Department of Civil Engineering, Universitas Katolik Parahyangan, Bandung, INDONESIA \\ Jalan Ciumbuleuit No. 94 Bandung \\ ${ }^{*}$ Corresponding authors: kelsentrista13@gmail.com
}

SUBMITTED 16 June 2020 REVISED 4 August 2020 ACCEPTED 21 August 2020

\begin{abstract}
The use of a non-prismatic member such as a stepped beam as a design method has the ability to function as a tool for steel beams optimization. A cover plate is partially welded on the upper and lower flange of the member at the maximum bending moment location to increase its flexural strength and, under critical load, flexural members bend about its strong axis, displace to the lateral direction, and twist coincidentally through a phenomenon known as the Lateral-Torsional Buckling (LTB). There is, however, no equations in the AISC 360-16 specification to calculate the critical moment of a stepped beam $\left(M_{s t}\right)$. Therefore, this research focuses on developing $M_{s t}$ for a simply supported stepped beam which deforms on its shear center under static-transverse loading through the use of a collapse analysis and the behavior of the beam. The results showed the welded cover plates consequently increased the LTB resistance of the prismatic I-shaped steel beam from $9.8 \%$ to $202 \%$ while the critical moment increased more significantly with an increment in the ratio of the cover plate length to the unbraced length $(\alpha)$. The cover plate thickness was observed to have dominantly affected only a large $\alpha$ ratio while the post-buckling characteristic of large $\alpha$ showed a sudden collapse phenomenon. Furthermore, the LTB modification factor was generated in this study due to the initial geometrical imperfection from the first mode of Eigen shape with maximum amplitude $L_{b} / 2000$ $\left(C_{b 1}\right)$ and stepped beam shape $\left(C_{s t}\right)$ which were required to estimate the critical moment of a stepped beam based on the AISC equation for a prismatic beam.
\end{abstract}

KEYWORDS Stepped Beam, Lateral Torsional-Buckling, Collapse Analysis, Critical Moment, Modification Factor.

(c) The Author(s) 2020. This article is distributed under a Creative Commons Attribution-ShareAlike 4.0 International license.

\section{INTRODUCTION}

Steel has always been a useful material for building constructions compared to other materials due to some of its advantages such as the high strength-to-weight ratio required in long-span bridges, tall buildings, and poorsituated steel structures to provide high strength for them despite their small weights. There is, however, the need for additional steel to stiffen these structures against buckling caused by slenderness and which reduces their economic value (McCormac and Csernak, 2012).

Non-prismatic member is one of the substantial methods to provide more efficient steel design optimization and it involves partially fabricating web-tapered beams and welding cover plates. For instance, the web-tapered beam has a geometric deeper web section on the maximum bending moment segment and a shallow depth is required on the minimum. Moreover, this design involves the allocation of more strength and stiffness using minimum weight (Kaehler et al., 2011) with the ratio of bending moment to moment capacity becoming larger.

Welded cover plates are also applicable to the flanges section using the design which serves the same purpose as those web-tapered. Therefore, the beam which undergoes a sudden crosssectional change in a particular segment is commonly known as the stepped beam, and its failure and geometry in real practices which indicates the maximum bending moment on mid-span are presented in Figure 1. 

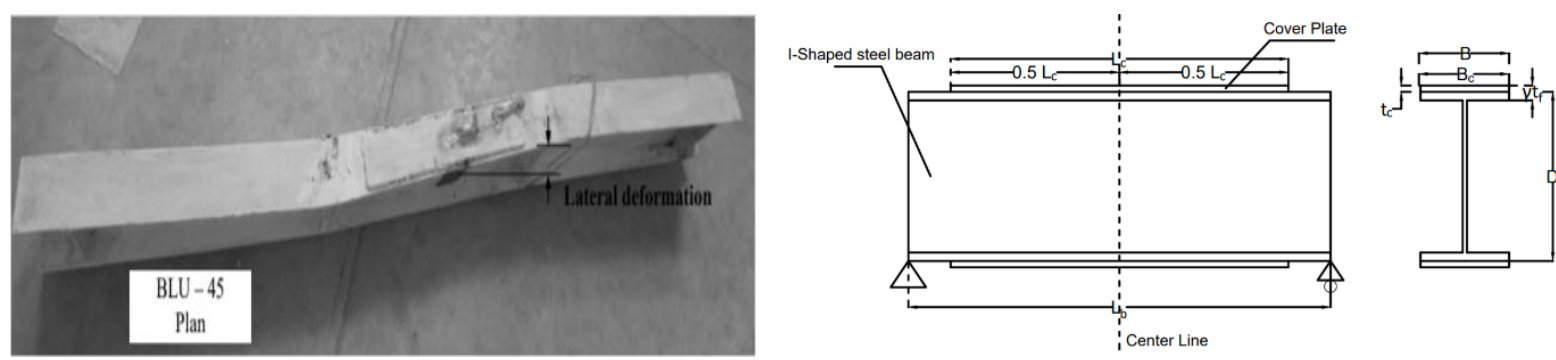

Figure 1. a) the failure mode of a stepped beam in real practice (Yossef, 2015) b) Geometry of a stepped beam.

Structural engineers prefer using stepped beams to web-tapered beams due to the lesser complexity in their fabrication as well as the Inexpensive cost of production (Park and Kang, 2004). This has led to an extensive understanding of the stepped beam by researchers as observed in the study of LTB simply supported stepped beam by generating the elastic buckling analysis by Trahair and Kitipornchai (1971). Moreover, Park and Kang (2004) proposed the critical moment of doubly and singly stepped beams located at the end supports with or without continuous lateral topflange bracing. Surla and Park (2015; 2014) proved the theoretical findings through the experimental study of lateral-torsional buckling strength of monosymmetric stepped I-beams. Recently, Alolod and Park (2018) examined the inelastic buckling capacity of the stepped beam at mid-span under a uniform moment. Meanwhile, AISC (2016) has considered a critical moment equation for prismatic flexural and webtapered members but none has been found for the critical moment of a stepped beam $\left(M_{s t}\right)$ which functions as a base to determine the flexural strength.

This study aimed to extend the findings of a previous study on stepped beam which was used to generate elastic buckling analysis to form the critical moment formula without considering the initial geometrical imperfection and residual stress effect. Therefore, the inelastic and elastic critical moment of simply supported stepped beam $\left(M_{s t}\right)$ located at mid-span under concentrated and uniformly distributed load was developed using Finite Element Analysis (FEA) as well as the collapse behavior of the beam. In addition, the research also examined the doubly- symmetric I-shaped beam with welded cover plates on its flanges and this is different from the investigation on stepped beam caused by the modification of the flange thickness conducted by other researchers.

The development of the modification factor for the LTB critical moment due to the effect of the cover plate added on upper and lower flange $\left(C_{s t}\right)$ and the initial geometrical imperfection $\left(C_{b 1}\right)$ through collapse analysis makes it possible to nearly approximate the critical moment of a stepped beam $\left(M_{s t}\right)$ to the value for the prismatic beam before the cover plates were added. $C_{s t}$ Is fundamentally defined as the ratio of the critical moment of the stepped beam $\left(M_{s t}\right)$ to the critical moment of the prismatic I-shaped member $\left(M_{c r}\right)$. Therefore, the $M_{s t}$ is obtainable using the following Equation (1).

$M_{s t}=C_{s t} \times C_{b 1} \times C_{b} \times M_{c r}$

\section{LITERATURE REVIEW}

\subsection{Lateral-Torsional Buckling}

The limit state of flexural members determines their nominal moment capacity. Therefore, the elastic LTB critical moment equation under a uniform bending moment diagram/pure bending is shown in Equation (2) (AISC, 2016).

$M_{c r}=\frac{\pi}{L_{b}} \sqrt{E I_{y} G J+\left(\frac{\pi E}{L_{b}}\right)^{2} I_{y} C_{w}}$

Where, $M_{c r}$ is the elastic LTB critical moment (Nmm), $L_{b}$ is the length between points braced either against the lateral displacement of compression flange or the twist of the crosssection (mm), $E$ is the Young's Modulus (200.000 $\mathrm{MPa}), I_{y}$ is the moment of inertia about the $y$-axis 
$\left(\mathrm{mm}^{4}\right), G$ is shear modulus (MPa), $J$ is torsional constant $\left(\mathrm{mm}^{4}\right)$, and $C_{w}$ is warping constant $\left(\mathrm{mm}^{6}\right)$.

AISC specification considered the nominal flexural strength of compact doubly-symmetric I-shaped steel beams and channels. Moreover, the plastic moment $\left(M_{\mathrm{p}}\right)$ and Lateral-Torsional Buckling (LTB) are the limit state for compact flexural members depending on their undergoing stresses and unbraced length $\left(L_{b}\right)$. The relationship between critical stress $\left(F_{c r}\right)$ and $L_{b}$ is, therefore, presented in the following Figure 2.

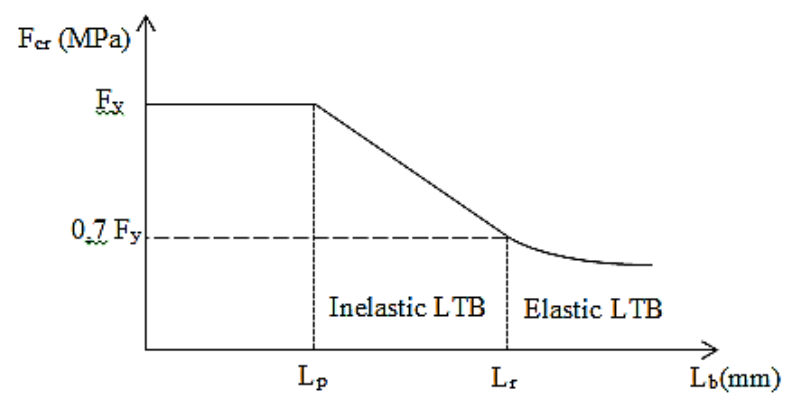

Figure 2. The relationship between critical stress $\left(F_{c r}\right)$ and unbraced segment length $\left(L_{b}\right)$ and its flexural limit states.

The flexural members experience inelastic LTB when $L_{p}<L_{b}<L_{r}$ as the critical moment is shown in Equation (3).

$M_{c r}=\left[M_{p}-\left(M_{p}-0.7 F_{y} S_{x}\right)\left(\frac{L_{b}-L_{p}}{L_{r}-L_{p}}\right)\right] \leq M_{p}$

\subsection{LTB modification factor $\left(C_{b}\right)$}

In most cases, Equation (2) usually produces a conservative result due to the fact that most beams are not subjected to uniform moment and most supports are not simple (Galambos and Surovek, 2008). The LTB modification factor $\left(C_{b}\right)$ was used for beams under a non-uniform bending diagram where both ends are restrained against lateral displacement or twist. Its critical moment is multiplied by the $C_{b}$ which was obtained using the Equation (4) (AISC, 2016).

$C_{b}=\frac{12.5 M_{\max }}{2.5 M_{\max }+3 M_{A}+4 M_{B}+3 M_{C}}$

Where $M_{\max }$ is the absolute value of maximum moment in the unbraced segment, $M_{A}$ is the absolute value of moment at the quarter-point of the unbraced segment, $M_{B}$ is the absolute value of moment at the centerline of the unbraced segment, and $M_{C}$ is the absolute value of moment at the three-quarter point of the unbraced segment.

\section{ANALYSIS METHOD}

Two methods were used for analysis in this study with the first being the bifurcation theory which is applicable only in an idealized beam with perfectly straight geometry, fully linear elastic material, and with the applied load resultant passing through the shear center. This theory leads to an Eigen problem which when solved produces Eigenvalue with the minimum value used as the elastic buckling load. The theory is also known as the linearized buckling due to the assumption of a small displacement assumption and this further makes the differential equation linear.

The second method is the collapse analysis procedure, and this involves an incremental increase in the applied load while the displacement is monitored until the beam completely collapses. Therefore, the output produces a load-displacement curve which Is further used to analyze the maximum applied load. Meanwhile, a beam with an initial geometrical imperfection from the bifurcation theory exhibits instability deformation and this means the maximum load on the curve as Indicated in Figure 3 is equal to the maximum buckling load.

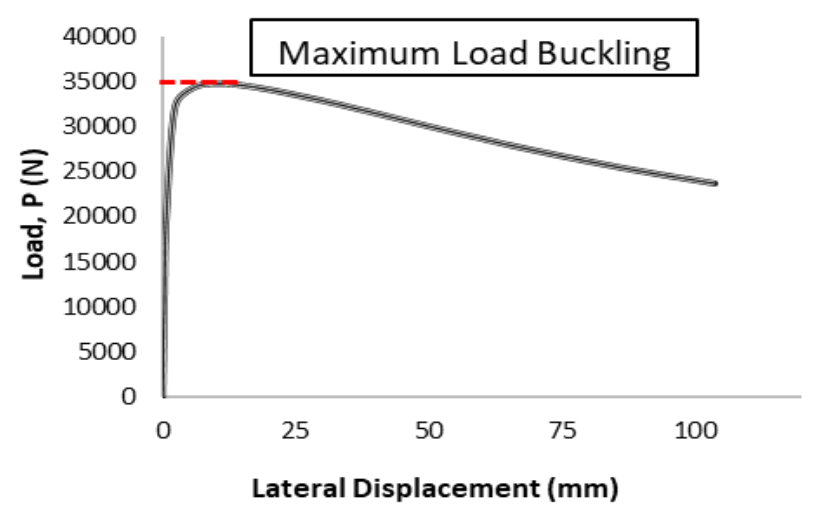

Figure 3. Maximum load buckling on the loaddisplacement curve. 
The collapse analysis was preferred in this study due to its similarity with real conditions as observed with most of the beams mostly having an initial imperfection due to fabrication as well as the inelastic and plastic behavior they experience after reaching the yield stress. Moreover, the use of large-displacement kinematics makes the differential equation nonlinear and this is suitable for analyzing inelastic buckling.

\section{FINITE ELEMENT MODELING}

The ADINA program was used as the non-linear analysis software and all the models used a 3D shell element with 4 nodes. The boundary conditions applied at both ends which are supported vertically using a pin-roller including full restraint on the torsional rotation and free warping.

\subsection{Rigid Link}

The stepped beam consisted of a prismatic Ishaped beam with the cover plates perfectly attached to the weld line. Meanwhile, the rigid link connections in FEM performed as the weld line on the periphery of the cover plate and the gap between the cover and flange plates was found to be 0 .

\subsection{Steel material}

The steel material has a true stress-strain curve with a yield stress $\left(F_{y}\right)$ value of $250 \mathrm{MPa}$ and also assumed to be plastic-multilinear, isotropic, homogenous, and linear. Meanwhile, every fabricated steel has residual stress before being subjected to any load due to the fabrication process. Moreover, the existing internal stress increases throughout the section up to the attainment of the critical stress during loading. The maximum residual stress of hot-rolled steel was valued at $0.3 \times F_{y}$ with a triangular linear pattern and Van der Aa (2015) has found the difference between the parabolic and triangular patterns of residual stress to be negligible. Therefore, a linear-triangular pattern was used in the FEM analysis as illustrated in Figure 4.

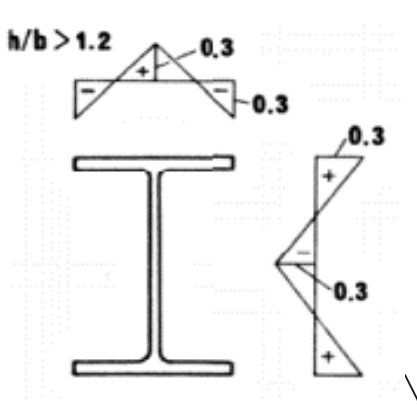

(a)

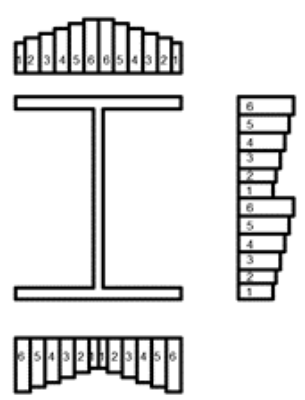

(c)

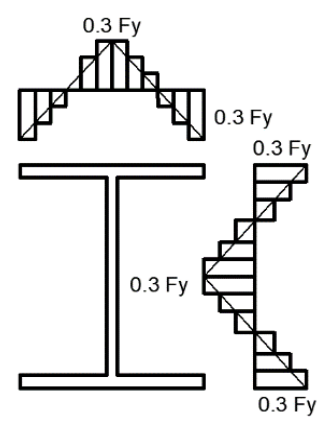

(b)
Figure 4. Residual stress patterns of the hot-rolled steel a) Triangular (Van der Aa, 2015) b) Stepwise; 2. The yield stress of steel material due to a positive bending moment influenced by residual stress

\subsection{Initial Geometrical Imperfection}

According to Salmon et al. (2008), the initial outof-straightness for $L / 1500$ amplitude has been calculated in the flexural column strength curves. Meanwhile, Dharma and Suryoatmono (2019) applied the initial out-of-straightness of $L / 1500$ value for the non-prismatic column to the node where the maximum scale of deformation pattern of the first mode of Eigen is located based on recommendation while the other nodes follow the geometrical imperfection shape. In this research, the FEM accommodates the initial imperfection of the first buckling mode of Eigen obtained from the linear buckling analysis and this shape has been reported to be the most suitable for LTB compared to others due to some certain reasons (Van der Aa, 2015). This theory has also been supported by Boissonnade and Somja (2012) in their journal.

The $L_{b} / 2000$ amplitude, which is smaller, was applied to a certain node where the maximum 
amplitude of the first mode of Eigen is located and it produced the insignificant reduction effect of the moment capacity of the stepped beam due to the incomplete consideration of any effect of the Initial geometrical imperfection by the theoretical solution of buckling. Therefore, the $C_{s t}$ equation was used accurately to approximate the moment of the stepped beam $\left(M_{s t}\right)$ from the theoretical solution $\left(M_{c r}\right)$ but the reduction effect due to the imperfection was considered. Figure 5 illustrates the initial geometrical imperfection on FEM.
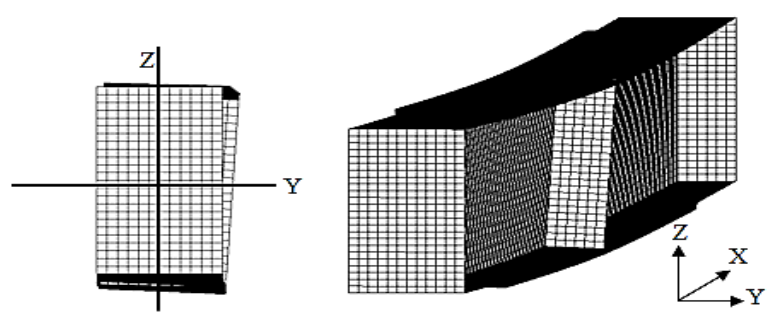

Figure 5. Initial geometrical imperfection following the first buckling mode of the Eigen Analysis (magnified).

\subsection{Loading}

The concentrated and the uniformly distributed loads were assigned to the models on the shear center as shown In Figure 6.

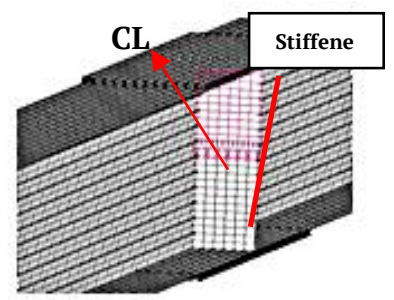

(a)

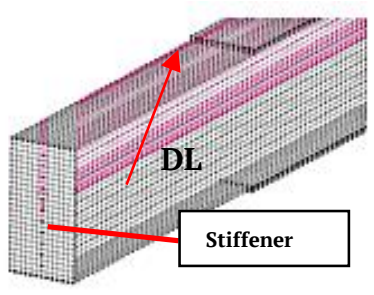

(b)
Figure 6. Applied load in FEM a) Concentrated load b) Uniformly distributed load.

The concentrated load requires a stiffener on mid-span to apply each nodal load throughout the stiffener for distribution to avoid the nodal stress concentration. Moreover, the stiffener also functions as a solidifier for the unstiffened element against local buckling.

\section{RESULT}

\subsection{Preliminary Verification}

The models were supposed to be verified before the parametric study and both the elastic critical moment of finite element analysis and Equation (2) or (3) from verification models presented in Table 1 were considered to verify the finite element models. Meanwhile, Table 1 shows the results based on linearized buckling from several verification models.

The verification results showed the deviation ranged from $-1.67 \%$ to $3.96 \%$. This small amount of numerical error indicates the accuracy and validity of the model with all its assumptions as defined in Chapter 4 and this means it should be continuously applied in this study for further analysis. Moreover, the first buckling mode shape based on the linearized buckling results is shown in Figure 7.

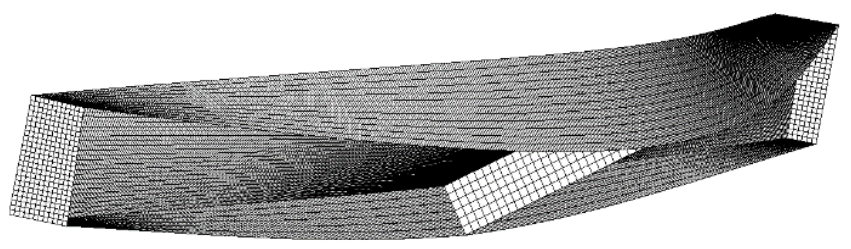

Figure 7. First buckling mode shape obtained from linearized buckling analysis.

The WF 400X200 finite element models were tested in relation to the collapse analysis verification and results are presented in the following Table 2 .

Table 1. Linearized buckling analysis results for verification models. , _.....,

\begin{tabular}{llllll}
\hline Section & Load & $L_{b}(\mathrm{~m})$ & $M_{0 c r}(\mathrm{kNm})$ & $C_{b \times} M_{c r}(\mathrm{kNm})$ & \%dev. $^{*}$ \\
\hline \multirow{4}{*}{ WF 400X200 } & \multirow{2}{*}{ CL } & 7 & 262.4 & 255.9 & 2.53 \\
& & 9 & 199.4 & 193.6 & 2.99 \\
\cline { 2 - 6 } & \multirow{2}{*}{ DL } & 10 & 177.4 & 178.9 & -0.87 \\
\hline & & 11 & 116.6 & 134.2 & -1.67 \\
& & 12 & 104.5 & 106.6 & -1.61 \\
\hline
\end{tabular}


Table 1. Linearized buckling analysis results for verification models. (Cont.)

\begin{tabular}{llllll}
\hline Section & Load & $L_{b}(\mathrm{~m})$ & $M_{0 c r}(\mathrm{kNm})$ & $C_{b x} M_{c r}(\mathrm{kNm})$ & $\% \mathrm{dev}$. \\
\hline \multirow{4}{*}{ WF 200X125 } & & 5 & 63.6 & 61.5 & 3.47 \\
& & 6 & 50.2 & 48.4 & 3.72 \\
& & 7 & 41.5 & 39.9 & 3.96 \\
\cline { 2 - 6 } & \multirow{2}{*}{ DL } & 8 & 29.9 & 29.4 & 1.88 \\
& & 9 & 26.1 & 25.6 & 1.96 \\
\hline
\end{tabular}

$* \%$ deviation $=\frac{c_{b} \times \mathrm{M}_{c \mathrm{r}}-\mathrm{M}_{\mathrm{ocr}}}{\mathrm{M}_{\mathrm{ccr}}} \times 100 \%$

Table 2. Collapse analysis results for verification models.

\begin{tabular}{llllll}
\hline Loading & $A_{y}(\mathrm{~mm})$ & $L_{b}(\mathrm{~m})$ & $M_{\text {ocr }}(\mathrm{kNm})$ & $C_{b \times} M_{c r}(\mathrm{kNm})$ & \%dev." \\
\hline \multirow{3}{*}{ CL } & 2 & 10 & 154.600 & 155.375 & -0.50 \\
& 2.2 & 11 & 138.973 & 137.310 & 1.21 \\
& 2.4 & 12 & 125.860 & 123.050 & 2.28 \\
\multirow{3}{*}{ DL } & 2.6 & 13 & 97.132 & 96.312 & 0.85 \\
& 2.8 & 14 & 89.868 & 88.095 & 2.01 \\
& 3 & 15 & 82.921 & 81.202 & 2.12 \\
\hline
\end{tabular}

* $A_{y}$ is $L_{b} / 5000$ initial geometrical imperfection amplitude

All the models have the maximum initial geometrical imperfection $L_{b} / 5000$ and the values obtained were relatively small to Indicate the insignificant effect of imperfection on the critical moment. Moreover, the verification through collapse analysis showed the models are accurate and reliable with a maximum deviation of $2.28 \%$. The results are similar to linearized buckling results and the theoretical solution (equation 2), therefore, WF 250X125 verification through collapse analysis was not conducted due to the possibility of making reference to the linearized buckling results. Meanwhile, the second verification was conducted on several models for the rigid link and the findings are presented in Table 3.

Table 4 compares the critical moment of a model with the rigid link connection applied to the cover plate periphery nodals and the models with the thickness of flanges taken as total thickness.
The results showed an insignificant difference In the values of $M_{c r_{-} r}$ and $M_{c r l}$ and this means the effect of the unconnected plane between the cover plate and flange is negligible while the beam especially experienced a torsional moment in FEM.

Table 3. Verification models for studying rigid link behavior.

\begin{tabular}{llll}
\hline Section & $A_{y}(\mathrm{~mm})$ & $t_{c}(\mathrm{~mm})$ & $\mathrm{L}_{\mathrm{b}}(\mathrm{m})$ \\
\hline \multirow{4}{*}{ WF 250 x 125 } & 4 & 5 & 8 \\
& 3 & 5 & 6 \\
& 2.5 & 5 & 5 \\
& 2 & 5 & 4 \\
\hline WF 400 x 200 & 6 & 8 & 12 \\
& 5 & 8 & 10 \\
& 2.5 & 8 & 6 \\
\hline
\end{tabular}

* $A_{y}$ is $L_{b} / 2000$ initial geometrical imperfection amplitude

${ }^{*} t_{c}$ is the cover plate thickness (mm) 
Table 4. Collapse analysis result on the rigid link verification.

\begin{tabular}{lllllll}
\hline & $A_{y}(\mathrm{~mm})$ & $t_{c}(\mathrm{~mm})$ & $L_{b}(\mathrm{~m})$ & $M_{r_{-} R L}(\mathrm{kNm})$ & $M_{c r 1}(\mathrm{kNm})$ & $\%$ Dev. \\
\hline \hline \multirow{2}{*}{ WF 250 x 125 } & 4 & 5 & 8 & 64.143 & 66.157 & -3.04 \\
& 2.5 & 5 & 6 & 78.969 & 82.653 & -4.46 \\
& 2 & 5 & 5 & 87.598 & 93.238 & -6.05 \\
WF 400 x 200 & 5 & 4 & 97.209 & 105.475 & -7.84 \\
\hline & 5 & 8 & 12 & 247.300 & 252.860 & -2.20 \\
& 2.5 & 8 & 10 & 293.825 & 292.981 & 0.29 \\
& 8 & 6 & 5 & 412.146 & 402.043 & 2.51 \\
\hline
\end{tabular}

Note:

$M_{c r_{-} R L}=$ the critical moment of a model with a rigid link connection on the cover plate periphery nodals (Nmm)

$M_{c r 1}=$ the critical moment of a model with flanges thickness taken as total thickness (Nmm)

$\%$ deviation $=\frac{\text { Mcr_RL }_{-} \text {Mcr1 } 1}{\text { Mcr1 }} \times 100 \%$

\subsection{Parametric Study}

A previous study by Park and Kang (2004) showed the effect of adding cover plates to the critical moment of a stepped beam depends on Its unbraced segment length $\left(L_{b}\right)$, cover plate thickness $\left(t_{c}\right)$, and its width $\left(b_{c}\right)$. This study only discusses the effect of length and thickness with both written in ratios such that parameter $\alpha$ represents the ratio of the cover plate length to the beam length and $\beta$ Indicates the ratio of the cover plate width to flange width while the total thickness of the profile flange thickness was notated as $\gamma$. The illustration of the whole parameters Is shown In Figure 1.

The ratio of the unbraced length to section height $\left(L_{b} / D\right)$ is a prismatic beam dimensionless parameter in the analytical model while the cover plate parameters for each $L_{b} / D$ value including $25,21.25,17.5,15,12.5$, and 10 in WF $400 \times 200$ are presented in Table 5 .
Table 5. Cover plates parameter for WF 400X200.

\begin{tabular}{lll}
\hline$\alpha$ & $\beta$ & $\gamma$ \\
\hline 0.167 & 1.00 & $1.50 ; 1.62 ; 1.77 ; 2.00$ \\
0.333 & 1.00 & $1.50 ; 1.62 ; 1.77 ; 2.00$ \\
0.700 & 1.00 & $1.50 ; 1.62 ; 1.77 ; 2.00$ \\
1.000 & 1.00 & $1.50 ; 1.62 ; 1.77 ; 2.00$ \\
\hline
\end{tabular}

Meanwhile, those for other values such as 32, 28, 24, 18, and 16 are presented in Table 6.

Table 6. Cover plates parameter for WF 250X125.

\begin{tabular}{lll}
\hline$\alpha$ & $\beta$ & $\gamma$ \\
\hline 0.167 & 1.00 & $1.56 ; 1.72 ; 1.89$ \\
0.333 & 1.00 & $1.56 ; 1.72 ; 1.89$ \\
0.700 & 1.00 & $1.44 ; 1.72 ; 2.00$ \\
1.000 & 1.00 & $1.44 ; 1.72 ; 2.00$ \\
\hline
\end{tabular}

The collapse shapes of the stepped beam due to the concentrated and uniformly distributed load and based on the collapse analysis are shown in Figures 8 and 9. 


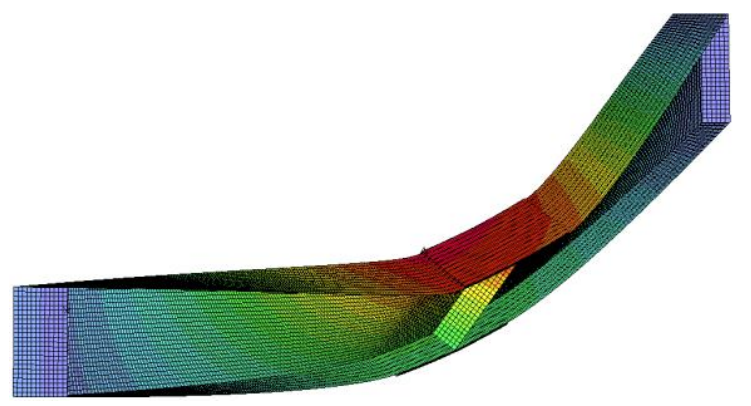

(a)

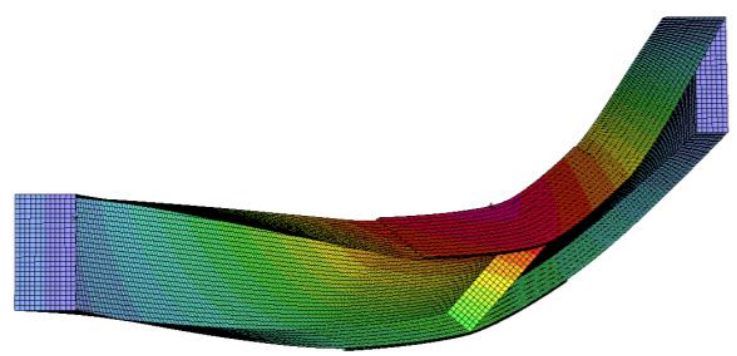

(b)

Figure 8. The collapse shape of the WF 400×200 stepped beam for a) $\alpha=0.167 \mathrm{~b}$ ) $\alpha=0.333$.

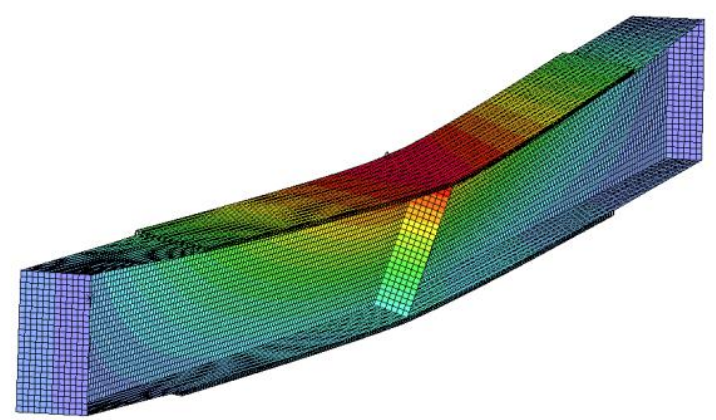

(a)

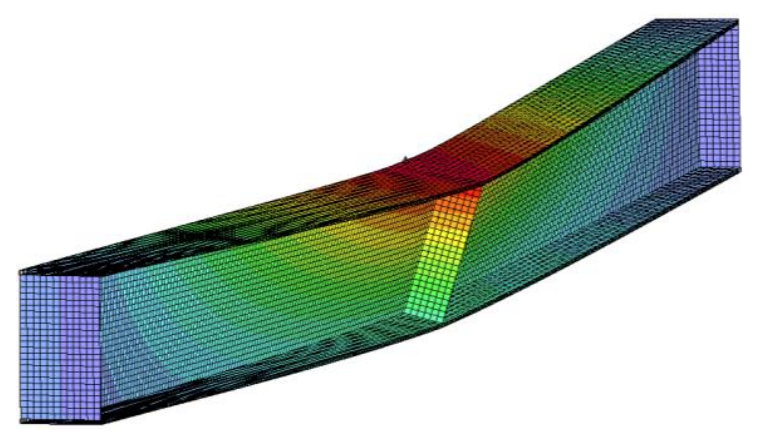

(b)

Figure 9. The collapse shape of the WF $400 \times 200$ stepped beam for a) $\alpha=0.700$ b) $\alpha=1.000$.

The results on the effects of the parameters are visualized into the data distribution graphs with Figure 10 depicting the $M_{s t}$ Vs $L_{b}$ curves obtained from the collapse analysis of the stepped beam under concentrated load on the shear center.

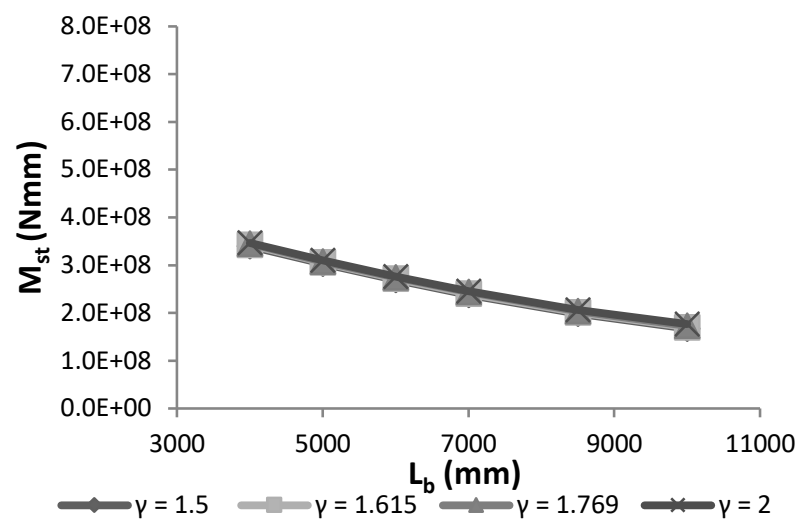

(a)

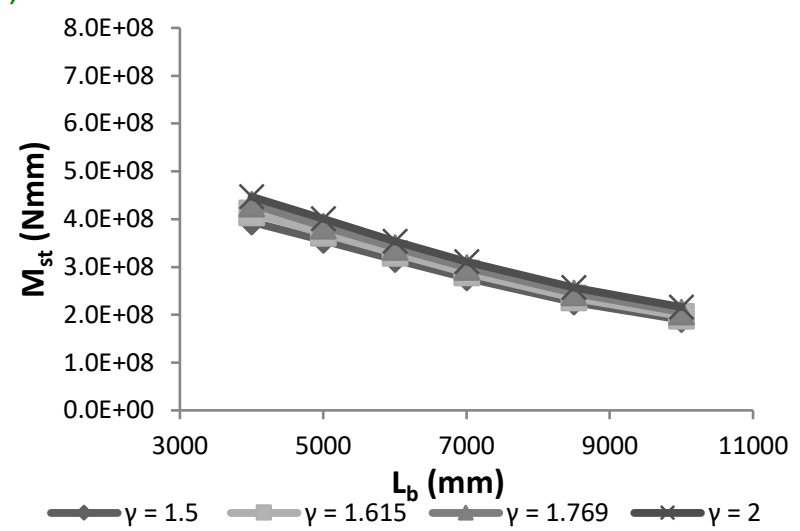

(b)

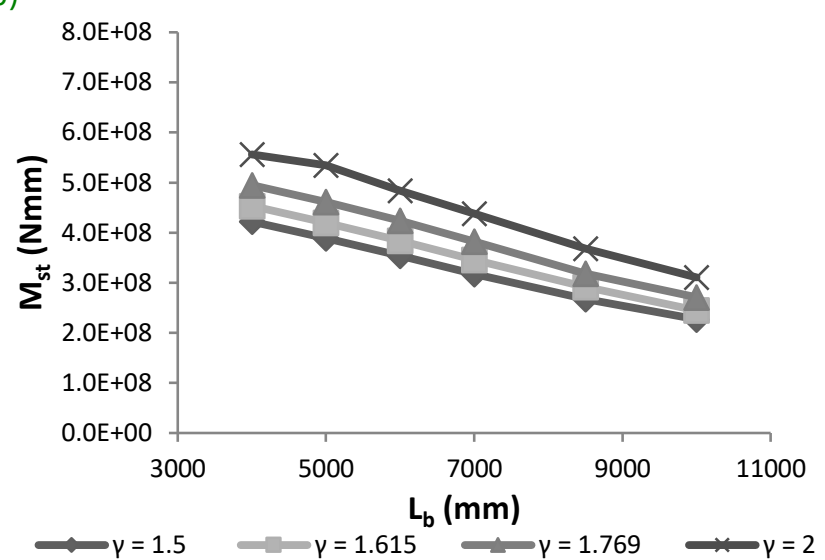

(c)

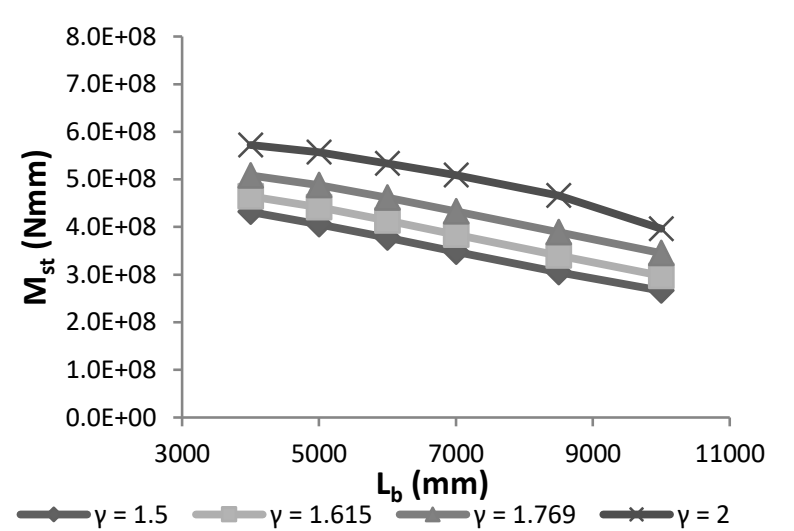

(d)

Figure 10. The relationship between $\mathrm{M}_{\text {st }}$ and stepped beam parameters on WF $400 \times 200$ stepped beam for a) $\alpha=0.167$ b) $\alpha 0.300$ c) $\alpha=0.700$ d) $\alpha=1.000$. 


\section{DISCUSSION}

\subsection{Stepped beam}

The collapse shapes in Figures 9 show the maximum lateral displacement of $0.167,0.333$, 0,700 , and $1,00 \alpha$ ratios occurred in the mid-span and this is in accordance with the theoretical LTB deformed shape. Therefore, there Is no particular concern in the discussion of the stepped beam collapse shape. Moreover, Figure 11 shows the load vs. lateral displacement ( $P-\delta$ curve) for several $\alpha$ values.

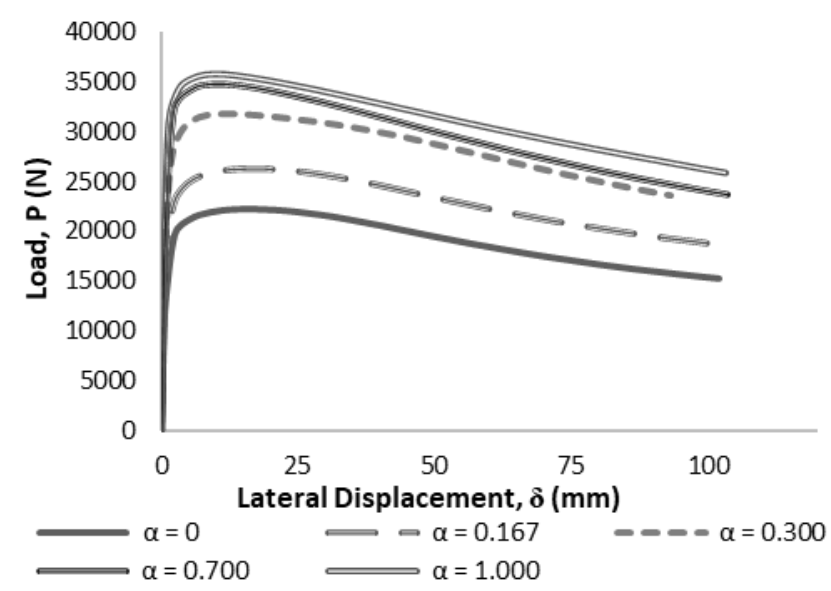

Figure 11. The relationship between load (P) and lateral displacement $(\delta)$ for different $\alpha$ ratios.

The graph clearly shows a greater value of $\alpha$ leads to a higher value for the critical load $\left(P_{c r}\right)$ and this means an increase in the $\alpha$ ratio has the ability to create a sudden collapse of the beam. This is evident from the slope of the curve after the critical load is reached and a beam was observed to have deformed significantly while the current load decreased suddenly. This is a post-buckling characteristic of the sudden collapse phenomenon but a smaller $\alpha$ ratio has a slight slope after the buckling point.

The effect of $\gamma$ for each group of $\alpha$ is indicated in the distribution of data vertically connected by lines under both concentrated and distributed loads as in Figure 10. The influence of $\gamma$ for $\alpha \leq$ 0.333 was found to be very insignificant with respect to $M_{s t}$ but more influence was observed at larger $\alpha$. This means $\alpha$ is strongly dominant in the stepped beam design due to the ability of Its ratio to determine the effect of the cover plate thickness on the section properties.

The torsion and warping constant are crosssectional properties used in determining the torsional stiffness of a beam. The addition of the cover plate along the flange significantly increased the critical moment of the LTB due to the Increment In the torsional stiffness. However, the length of the cover plate in a portion of the span length has an enormous effect on the intended stiffness.

\subsection{Coefficient analysis}

The rearrangement of the linear relationship in Equation (1) made the modification factor for the critical moment of the prismatic beam due to the addition of the partial cover plate on the upper and lower flange is shown in Equation (5).

$C_{s t}=\frac{M_{s t}}{M_{0 c r}}$

In terms of ratio, it is possible to completely eliminate the effect of the initial geometrical imperfection and the numerical error while the proposed equation of $C_{s t}$ was obtained from the regression model of the 312 projected in a linear equation and second-degree polynomial using $\alpha$, $\gamma$, and $L_{b} / D$ as the variables. Figure 12 , however, represents the effect of $\alpha, \gamma$, and $L_{b} / D$ variables with respect to $C_{s t}$.

The $C_{s t}$ equation was grouped into $\alpha \leqslant 0.333$ and $\alpha>0.333$ due to the dominant effect of the $L_{b} / D$ ratio on $\alpha>0.333$ and a small effect on $\alpha \leqslant 0.333$. Accordingly, the equation for $\alpha \leqslant 0.333$ eliminated the small effect of $L_{b} / D$ and the proposed equation of $C_{s t}$ in the regression model is presented in Figures 13 and 14. 


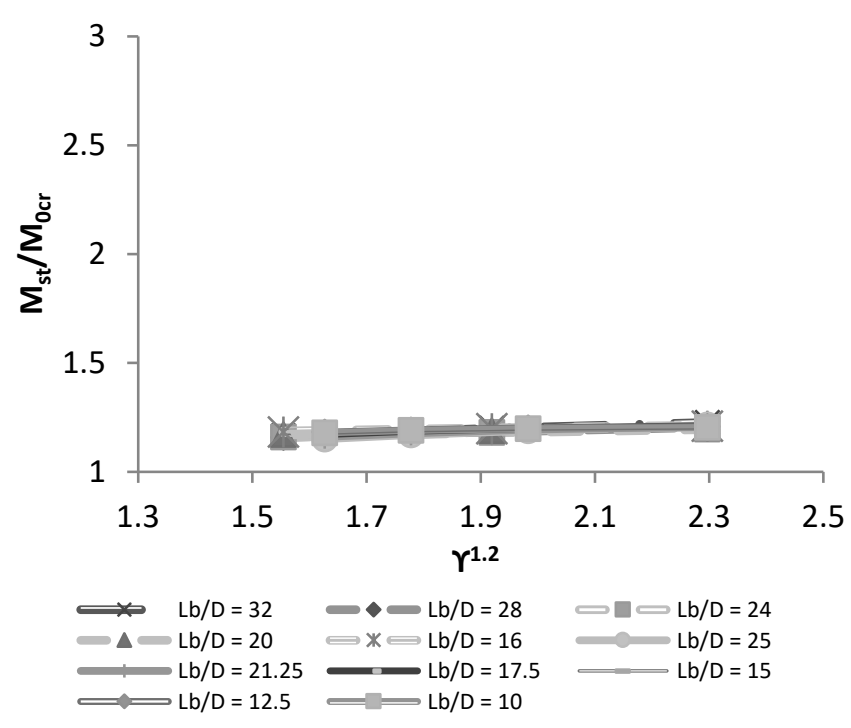

(a)

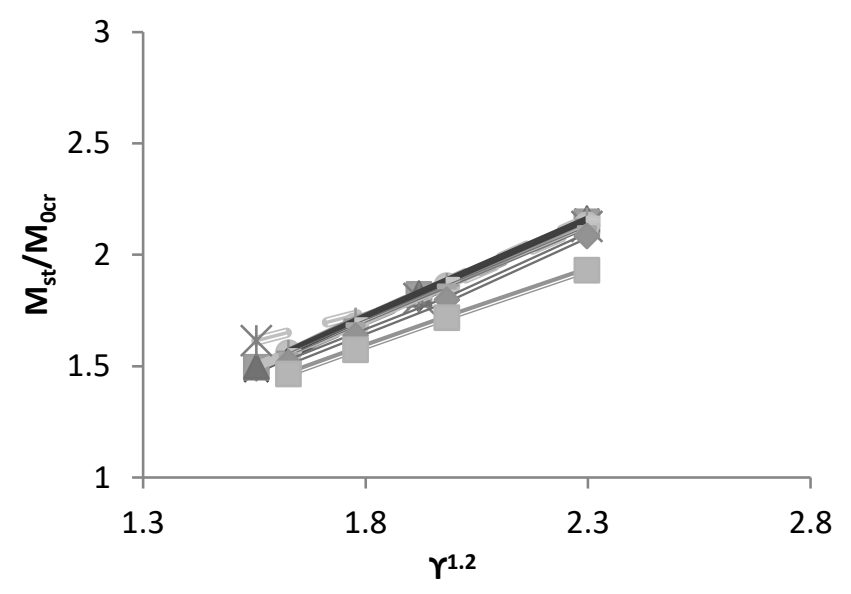

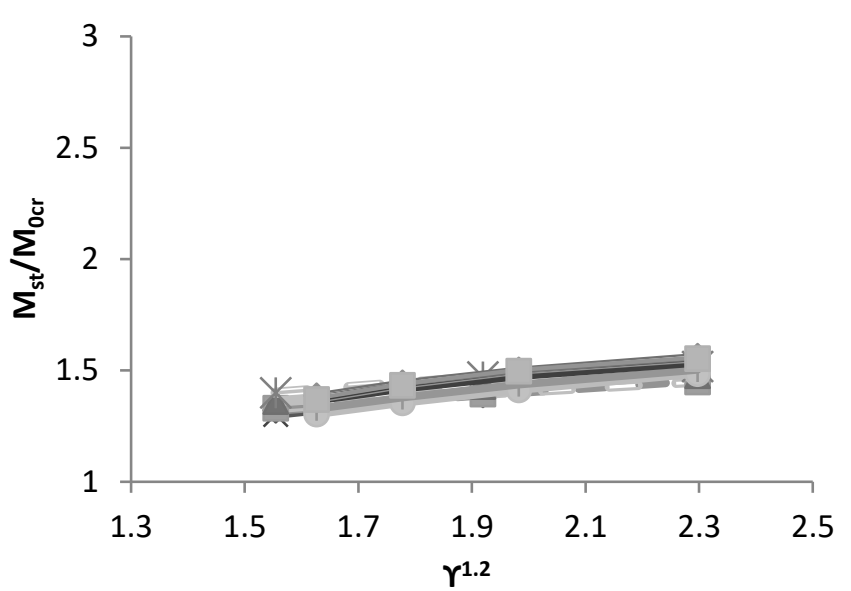

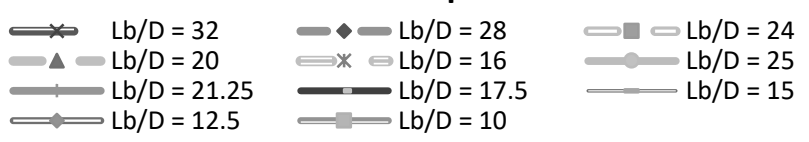

(b)

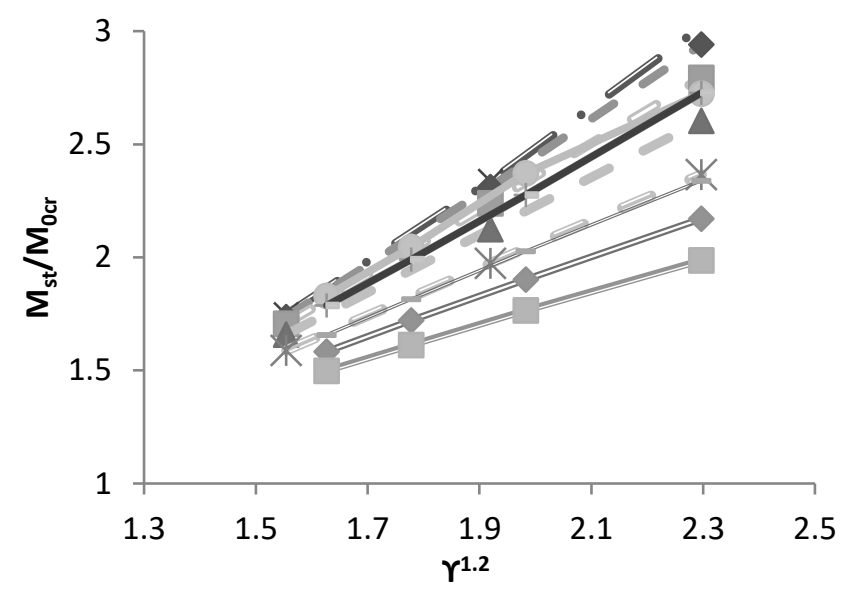

(c)

(d)

Figure 12. The relationship between all the parameters with respect to $C_{\text {st }}$ for a) $\alpha=0.167$ b) $\alpha=0.300$ c) $\alpha=0.700$ d) $\alpha=$ 1.000 .

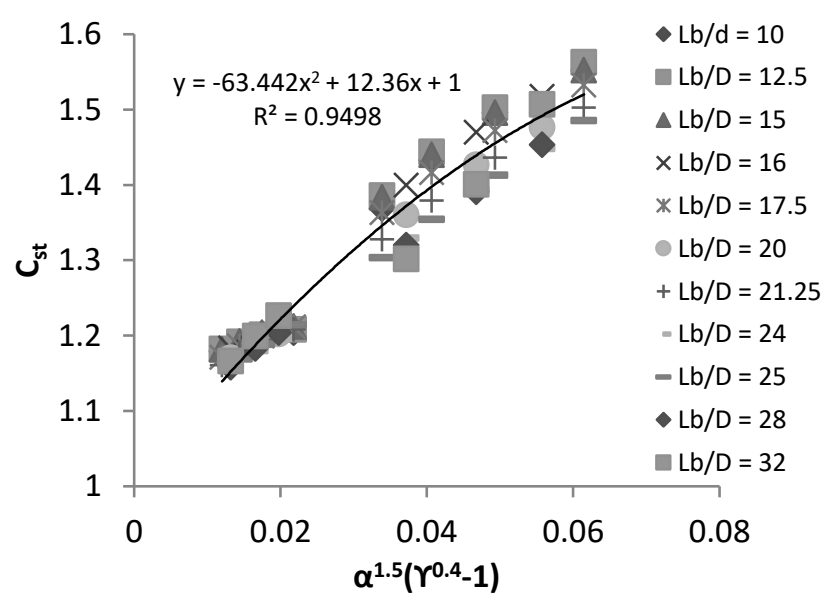

(a)

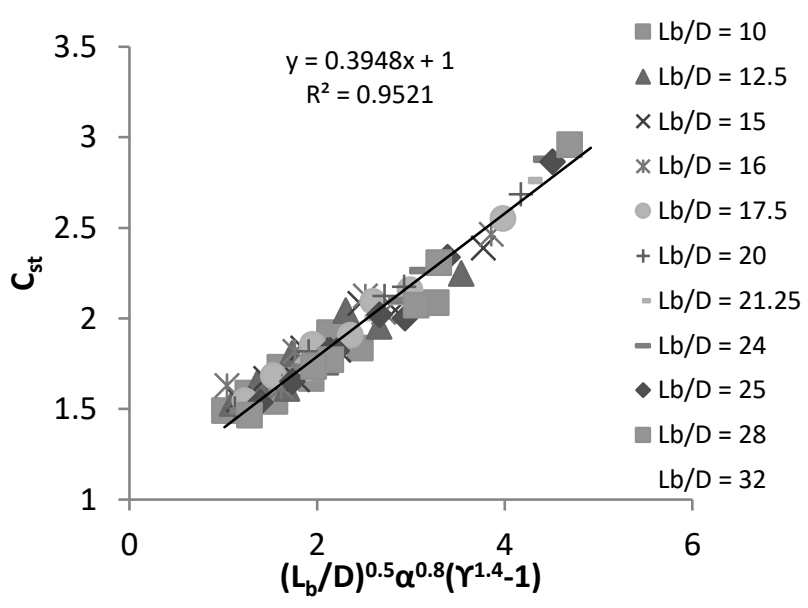

(b)

Figure 13. Regression model of $C_{\text {st }}$ for the stepped beam under concentrated load for a) $\alpha \leq 0.333$ b) $\alpha>0.333$. 


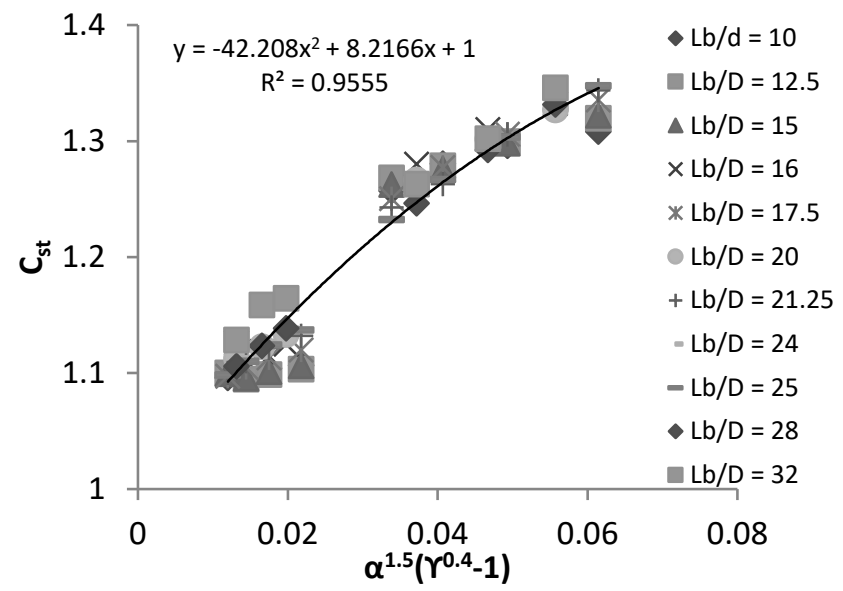

(a)

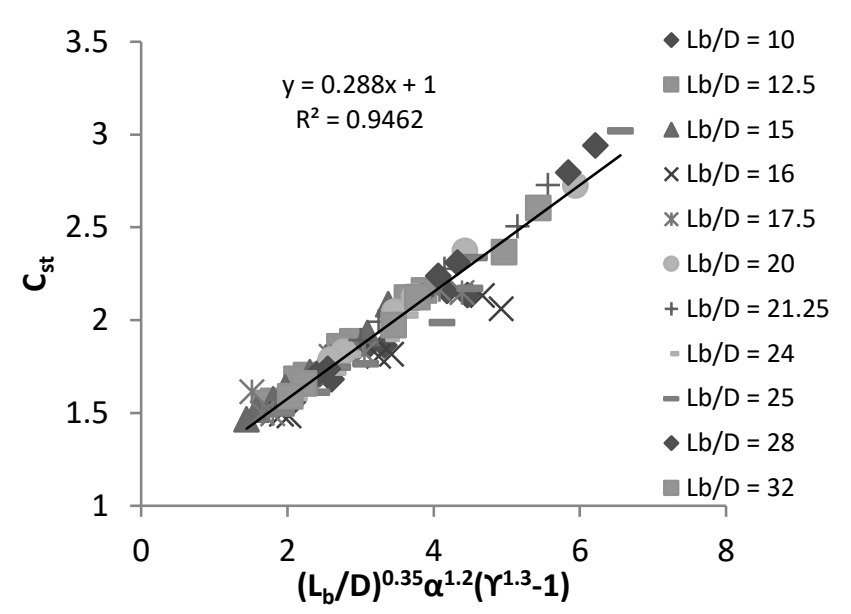

(b)

Figure 14. Regression model of $C_{\text {st }}$ for the stepped beam under distributed load for a) $\alpha \leq 0.333$ b) $\alpha>0.333$.

The $C_{s t}$ equations were proposed reasonably according to the accuracy of each regression model and summarized in Table 8. Moreover, all the finite element models contain the initial geometrical imperfections following the first buckling mode shape with $L_{b} / 2000$ amplitude. This, of course, influences the load-bearing capacity of the stepped beam due to the occurrence of excessive stress before the steel material reaches its yield stress. Therefore, the LTB modification factor coefficient due to the initial geometrical was required and the equation between the critical moment including the initial geometrical imperfection of $L_{b} / 2000\left(M_{\text {ocr }}\right)$ and the Idealized one (Equations $2 \& 3$ ) is presented as Equation (6).

$M_{0 c r}=C_{b 1} \times C_{b} \times M_{c r}$

Figure 15 shows the proposed equation of $C_{b 1}$ vs dimensionless unit $\left(L_{b} / L_{r}\right)$ with the initial geometrical imperfection coefficient expected to be limited by 1 .

\section{SUMMARY}

The research showed several conclusions concerning the LTB of the stepped beam and the major summary is the possibility of determining the critical moment of the stepped beam $\left(M_{s t}\right)$ using the Equation (7).

$M_{s t}=C_{s t} \times C_{b 1} \times C_{b} \times M_{c r}$

The $\gamma$ ratio or cover plate thickness only has a significant effect on the critical moment of stepped beams $\left(M_{s t}\right)$ in the greater $\alpha$ ratio $(\alpha>$ $0.333)$. Therefore, it is possible to obtain the optimum cover plate thickness for $\alpha \leq 0.333$ from the minimum thickness of the compactness requirements of AISC 360-16. In addition, the inelastic post-buckling characteristic showed a sudden collapse for $\alpha>0.700$, and the rigid link connection was found to be applicable as a welding line in FEM. However, the unconnected nodes between the cover plate and flange do not affect the critical moment even though it experiences a torsional moment. 


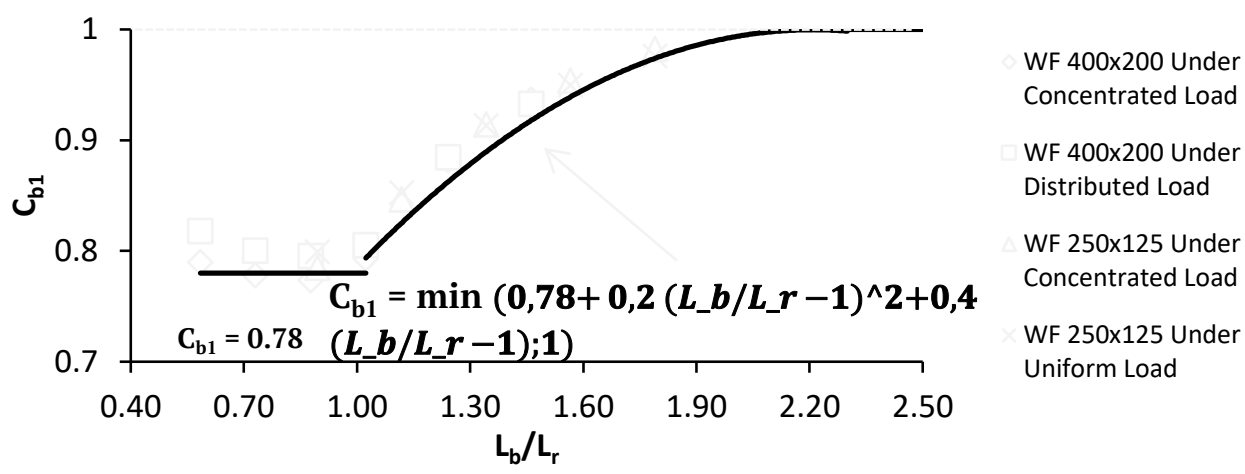

Figure 15. Proposed $C_{b 1}$ equations for the stepped beam that experienced inelastic or elastic LTB.

Table 7. The proposed equations of $\mathrm{C}_{\text {st }}$ for concentrated and uniformly distributed load classified by a ratio.

\begin{tabular}{llll}
\hline \multirow{2}{*}{ Loading } & \multirow{2}{*}{ Classification } & Proposed Equations & \\
\cline { 3 - 4 } & & $X$ & $C_{s t}$ \\
\hline \multirow{2}{*}{ Concentrated Load } & $\alpha \leqslant 0.333$ & $\alpha^{1.5}\left(\gamma^{0.4}-1\right)$ & $-63.4 \mathrm{X}^{2}+12.3 \mathrm{X}+1$ \\
& $\alpha>0.333$ & $\left(\mathrm{~L}_{\mathrm{b}} / \mathrm{D}\right)^{1 / 2} \alpha^{0.8}\left(\gamma^{1.4}-1\right)$ & $0.395 \mathrm{X}+1$ \\
\hline \multirow{2}{*}{ Distributed Load } & $\alpha \leqslant 0.333$ & $\alpha^{1.5}\left(\gamma^{0.4}-1\right)$ & $-42.2 \mathrm{X}^{2}+8.2 \mathrm{X}+1$ \\
& $\alpha>0.333$ & $\left(\mathrm{~L}_{\mathrm{b}} / \mathrm{D}\right)^{0.35} \alpha^{1.2}\left(\gamma^{1.3}-1\right)$ & $0.288 \mathrm{X}+1$ \\
\hline
\end{tabular}

\section{DISCLAIMER}

The authors declare no conflict of interest.

\section{ACKNOWLEDGEMENTS}

The authors appreciate the Universitas Katolik Parahyangan for allowing the usage of their ADINA program.

\section{REFERENCES}

American Institute of Steel Construction, 2016. Specifications for Structural Steel Buildings, ANSI-AISC 360-16, AISC (American Institute of Steel Construction).

Alolod, S. \& Park, J. S. 2018. Inelastic Buckling Strength of Stepped I-Beams at Midspan Subjected to Uniform Bending. Journal of the Korean Society of Hazard Mitigation, 18, 185-192.

Boissonnade, N. \& Somja, H. Influence of imperfections in FEM modeling of lateral torsional buckling. Proceeding of the Annual Stability Conference Structural Stability Research Council, 2012. 18-21.

Dharma, A. P. \& Suryoatmono, B. Non-Linear Buckling Analysis of Axially Loaded Column with
Non-Prismatic I-Section. Journal of the Civil Engineering Forum, 2019. 263-274.

Galambos, T. V. \& Surovek, A. E. 2008. Structural stability of steel : concepts and applications for structural engineers, Hoboken, N.J., John Wiley \& Sons.

Kaehler, R., White, D. \& Kim, Y. 2011. Steel design guide 25 ; frame design using web-tapered members. AISC, Chicago.

Mccormac, J. C. \& Csernak, S. F. 2012. Structural steel design, Harlow, Pearson Education.

Park, J.-S. \& Kang, Y.-J. 2004. Lateral Buckling of Stepped Beams under Linear Moment Gradient. Journal of Steel Structures, KSSC, 4, 71-81.

Salmon, C. G., Johnson, J. E. \& MALHAS, F. A. 2008. Steel structures : design and behavior, Indianapolis, Ind., Prentice Hall.

Surla, A. \& Park, J. 2015. Investigation of Effect of Steps in Inelastic-Buckling Strength of IBeams Subjected to Two Concentrated Loads Using Experimental Tests, Finite Element Analysis and Proposed Equations. Journal of Korean Society of Hazard Mitigation, 15, 1-12. 
Surla, A. S. \& Park, J. S. 2014. Investigation of lateral-torsional buckling strength trends in monosymmetric stepped I-beams subjected to several loading conditions. Journal of the Korean Society of Hazard Mitigation, 14, 33-42.

Trahair, N. S. \& Kitipornchai, S. 1971. Elastic lateral buckling of stepped I-beams. Journal of the Structural Division, 97, 2535-2548.
Van Der AA, R. 2015. Numerical assessment of the design imperfections for steel beam lateral torsional buckling. Master thesis A-2015.102.

Yossef, N. 2015. Strengthening Steel I-Beams by Welding Steel Plates before or While Loading. International Journal of Engineering Research \& Technology (IJERT), 4, 545-550. 
[This page is intentionally left blank] 